\title{
Multiple actions of the chemokine stromal cell-derived factor- $1 \alpha$ on neuronal activity
}

\author{
Alice Guyon and Jean-Louis Nahon \\ CNRS UMR 6097, Institut de Pharmacologie Moléculaire et Cellulaire, Sophia Antipolis, 660 route des Lucioles, 06560 Valbonne, France \\ (Requests for offprints should be addressed to A Guyon; Email: alice.guyon@ipmc.cnrs.fr)
}

\begin{abstract}
The chemokine SDF- $1 \alpha$ and its cognate receptor CXCR4 are expressed in several neuronal populations. This review focuses on our current knowledge about the actions of this chemokine on neuronal excitability, through CXCR4 or other yet unknown pathways. In various neuronal populations (CA1 neurons of the hippocampus, granular and Purkinje cells of the cerebellum, melanin-concentrating hormone neurons of the lateral hypothalamus, vasopressinergic neurons of the supraoptic and the paraventricular nucleus of the hypothalamus, and dopaminergic neurons of the substantia nigra), SDF- $1 \alpha$ can modulate the activity of neurons by multiple regulatory pathways including and often combining: (i) modulation of voltage-dependent channels (sodium, potassium, and calcium), (ii) activation of the G-protein-activated inward rectifier potassium current, and (iii) increase in neurotransmitter release (gamma-amino butyric acid (GABA), glutamate, and dopamine), often through Ca-dependent mechanisms. The possible mechanisms underlying these effects and their consequences in terms of modulation of neuroendocrine systems and physiopathology are discussed.
\end{abstract}

Journal of Molecular Endocrinology (2007) 38, 365-376

\section{Introduction}

Chemokines are small secreted proteins with chemoattractant properties for immune cells (Luster 1998, Luther \& Cyster 2001). At least 50 chemokines have been found to date and have been classified according to the number and spacing of the conserved cysteine residues at the $\mathrm{N}$-terminal position (Murphy et al. 2000). Phylogenic analyses showed that the large, highly redundant CXC chemokine family is a very recent phenomenon that is exclusive to higher vertebrates. Interestingly, its ancestral role might be within the central nervous system and not within the immune system (Huising et al. 2003). Chemokines exert their biological effects through cell surface receptors that belong to the superfamily of seven-membrane domain G-protein-coupled receptors (GPCRs). At least 22 chemokine receptors have been characterized, which are designed following chemokine nomenclature. Most chemokines bind to several chemokine receptors and most chemokine receptors recognize several chemokines (Bacon \& Harrison 2000). Besides their role in the immune system, chemokines and their receptors may play an important role in the central nervous system. For example, neurodegenerative and neuroinflammatory disorders, such as multiple sclerosis, Alzheimer's disease, Parkinson's disease, and human immunodeficiency virus (HIV)-associated dementia are commonly associated with local chemokine release (Streit et al. 2001, Vila et al. 2001, Lee et al. 2002, McGeer \& McGeer 2004, Cartier et al. 2005). However, the effects of these pro-inflammatory factors on neural activity remain elusive.

Among CXC chemokines, CXCL12/SDF-1 has attracted much attention. This chemokine was originally described as a secreted product of bone marrow stromal cell line (Tashiro et al. 1993). Three protein isoforms, SDF- $1 \alpha$, SDF-1 $\beta$, and SDF- $1 \gamma$, which arise from alternative mRNA splicing, have been characterized (Gleichmann et al. 2000, Pillarisetti \& Gupta 2001, Stumm et al. 2002); most studies have focused on SDF-1 $\alpha$, which is the object of this review.

In the nervous system, in situ hybridization and dual immunohistochemistry revealed that SDF- $1 \alpha$ is constitutively expressed not only in astrocytes and microglia but also in neurons, in discrete neuroanatomical regions (Stumm et al. 2002, Banisadr et al. 2003). Indeed, neuronal expression of SDF- $1 \alpha$ is found mainly in cerebral cortex, substantia innominata and medial septum, globus pallidus, hippocampus, paraventricular and supraoptic hypothalamic nuclei, lateral hypothalamus, substantia nigra $(\mathrm{SN})$, ventral tegmental 
area, and oculomotor nuclei (Banisadr et al. 2003). Overall, SDF-1 $\alpha$ appears to be expressed in cholinergic, monoaminergic, and neuropeptide-expressing neurons, raising the possibility that SDF- $1 \alpha$ could act as a neuromodulator (Banisadr et al. 2003, 2005a).

Until very recently, CXCR4 has been thought as the sole receptor for CXCL12/SDF-1 chemokine among six CXC receptors (Bajetto et al. 2001a, Bonavia et al. 2003). Another receptor for this chemokine has recently been described in $\mathrm{T}$ lymphocytes and named CXCR7 (Balabanian et al. 2005), but to date, there is no evidence of its presence in the normal brain.

CXCR4, as its ligand SDF- $1 \alpha$, is constitutively expressed by glial and neuronal cells in the CNS (Bajetto et al. 2001a, Bonavia et al. 2003). In situ hybridization and immunocytochemistry showed that CXCR4 neuronal expression was mainly found in cerebral cortex, globus pallidus, caudate putamen and substantia innominata (where CXCR4 immunoreactivity is co-localized with choline acetyltransferase immunoreactivity; Banisadr et al. 2002), supraoptic and paraventricular hypothalamic nuclei (where it is expressed in arginine-vasopressin (AVP) neurons; Banisadr et al. 2003), lateral hypothalamus (where CXCR4 is co-localized with neurons expressing the melanin-concentrating hormone (MCH); Guyon et al. $2005 b$ ), ventromedial thalamic nucleus, and SN (where CXCR4 is expressed on dopaminergic (DA) neurons of the pars compacta; Banisadr et al. 2002), and also on GABAergic neurons of the pars reticulata (Guyon et al. 2006) and in the cerebellum (where it is expressed both in the Purkinje neurons and granule cells and in the glial radial fibers; Ragozzino 2002). It is interesting to note that there is a co-distribution of CXCL12/SDF-1 and CXCR4 proteins in a number of brain regions, which strongly suggests that they could constitute together a functional receptor/ligand system in specific neuronal pathway.

CXCR4 activation by SDF-1 $\alpha$ activates multiple intracellular pathways (Lazarini et al. 2003). CXCR4 activation is coupled through pertussis toxin (PTX)sensitive $G$ proteins to at least two distinct signaling pathways. The first pathway, involving phosphatidylinositol-3 (PI-3) kinase and extracellular signal regulated kinase $($ ERK $) \frac{1}{2}$, has been described in rodent astrocytes, neuronal progenitors, and cortical neurons (Bacon \& Harrison 2000, Lazarini et al. 2000, Bajetto et al. 2001b, Bonavia et al. 2003). The other pathway involves the phospholipase $\mathrm{C} \beta$ whose activation leads to an increase in the intracellular calcium in astrocytes, cortical neurons, and cerebellar granule cell, as well as in primate fetal neuron and microglia (Bajetto et al. 1999, Klein et al. 1999, Zheng et al. 1999). The increase in calcium leads to the activation of proline-rich tyrosine kinase (PYK2), which may itself lead to ERK $1 \frac{1}{2}$ activation (Bajetto et al. 2001b). CXCR4 stimulation can directly modulate ionic channel of the plasma membrane in neurons, particularly highthreshold calcium channels (our results and Zheng et al. 1999), and this could also result in the intracellular calcium increase and PYK2 activation (Lazarini et al. 2003). Finally, in the primary cultures of neurons, CXCR4 can also inhibit cAMP pathways through the Gi component of GPCRs (Liu et al. 2003).

Under ligand stimulation, CXCR4 undergoes a desensitization and internalization. Signaling and internalization of CXCR4 are regulated by receptor phosphorylationdependent and -independent mechanisms. When independent of receptor phosphorylation, desensitization appears to be a consequence of the phosphorylation of phospholipase C $\beta 3$ (Haribabu et al. 1997).

SDF-1 $\alpha$ has been shown to exert various functions in the brain (Lazarini et al. 2003). SDF-1 $\alpha$ has proved to be a potent chemoattractant for primary mouse microglial cells, but not for astrocytes (Tanabe et al. 1997). SDF-1 $\alpha$ does not seem directly to be a chemoattractant for neurons, but it reduces axonal responsiveness to several known repellents (Chalasani et al. 2003a). SDF- $1 \alpha$ is synthesized constitutively in the developing brain and has an obligate role in the neuronal migration during the formation of the granule-cell layer of the cerebellum (Ma et al. 1998, Zou et al. 1998, McGrath et al. 1999) and other brain area (Tran \& Miller 2003). Indeed, mice that lack SDF1 or CXCR4 died soon after birth and showed major defects in their vascular, hemopoietic, and central nervous system, in particular, in cortex and cerebellum development (Nagasawa et al. 1998, Tachibana et al. 1998, Stumm et al. 2003). Apart from this role in angiogenesis and development, CXCR4 is a receptor for the GP120 protein of the HIV, thus being a co-receptor for HIV entry into target cells and was thus also named fusin (Feng et al. 1996, Doranz et al. 1997). Neurotoxic effects of CXCR4 activation have been extensively studied in relation to the involvement of CXCR4 in HIV-associated dementia (Kaul \& Lipton 2004, Khan et al. 2004). Massive stimulation of chemokine receptors during inflammatory processes may lead to apoptosis and neurodegeneration (Glabinski \& Ransohoff 1999). On the other hand, SDF- $1 \alpha$ is neuroprotective in cultured hippocampal neurons when apoptosis is stimulated by gp120 treatment (Meucci et al. 1998). In addition, SDF-1 $\alpha$ has strong survival-promoting effects on cultured embryonic retinal ganglion cells through an action on CXCR4 (Chalasani et al. 2003b).

The aim of this review is to summarize the recent data which show that the chemokine SDF-1 $\alpha$ can also modulate the activity of several neuronal populations that may have a role under physiological and/or pathological conditions. 


\section{Effects on neuronal activity and neuro- transmitter release}

Recently, SDF-1 $\alpha$ was shown to act in the brain as a neuromodulator (reviewed in Lazarini et al. 2003, Banisadr et al. 2005b). The effect of chemokines on neuronal activity has been studied using electrophysiological and/or calcium-imaging techniques.

SDF- $1 \alpha$ modulates the activity of vasopressinergic neurons recorded in the rat supraoptic and paraventricular nucleus slices through CXCR4, resulting in changes in the AVP release (Callewaere et al. 2006). SDF-1 $\alpha$ can blunt the autoregulation of AVP release in vitro and counteract angiotensin II-induced plasma AVP release in vivo. Furthermore, a short-term physiological increase in AVP release induced by enhanced plasma osmolarity was similarly blocked by central injection of SDF- $1 \alpha$ through CXCR4 and a change in water balance induced a decrease in both SDF- $1 \alpha$ and CXCR4 parallel to that of AVP immunostaining in supraoptic nucleus (Callewaere et al. 2006).

CXCR 4 and SDF- $1 \alpha$ are expressed in MCH neurons of the lateral hypothalamus (LHA), a peptide-expressing neuronal population mainly involved in feeding intake and energy storage regulation (reviewed in Nahon 2006). SDF- $1 \alpha$ exerts multiple effects on this neuronal system (Fig. 1A): using rat brain slices of hypothalamus in which $\mathrm{MCH}$ neurons were identified electrophysiologically and a posteriori by single-cell RT-PCR, we have shown that SDF$1 \alpha$ increases spontaneously glutamate and gamma amino butyric acid (GABA) release on these neurons and activates a G-protein-activated inward rectifier potassium (GIRK) current (Guyon et al. 2005b). SDF-1 $\alpha$ also modulates the action potential discharge of these neurons and interestingly, the effects vary as a function of the concentration (Guyon et al. 2005b): low concentrations $(0 \cdot 1-1 \mathrm{nM})$ decrease the frequency of discharge (Fig. 2B1), an effect blocked by the competitive antagonist AMD 3100, thus mediated through CXCR4, although this compound also has a weak partial agonist activity (Zhang et al. 2002). This decrease in frequency of discharge of action potentials is mediated through a decrease of voltage-gated sodium current and delayed rectifier-potassium current (thus inducing a slowing of the repolarization of the action potential; Guyon et al. $2005 a$ ). At the opposite, higher concentrations increase the frequency of discharge (Fig. 2B2), but this effect is not blocked by AMD 3100, suggesting that it is not mediated through CXCR4 (Guyon et al. 2005b). These different effects of SDF- $1 \alpha$ were recently confirmed by our group using brain slices from transgenic mice expressing the green fluorescent protein (GFP) under the promotor of $\mathrm{MCH}$ gene, a transgenic mouse model kindly provided by Prof. Jeffrey Friedman's laboratory, where MCH neurons can be easily identified before electrophysiological recordings (Fig. 2A1-A7).
SDF-1 $\alpha(25 \mathrm{nM})$ can enhance the excitatory synaptic transmission in rat hippocampus (Fig. 1B). This effect was antagonized by $\omega$-conotoxin GVIA, a N-type calcium channel antagonist, and by 12G5, a specific antibody against CXCR4, suggesting that SDF- $1 \alpha$ acted through a CXCR4-mediated increase in intracellular calcium through N-type Ca currents (Zheng et al. 1999). However, in embryonic primary cultures of rat hippocampus, SDF-1 $\alpha$ at higher concentrations (50-100 nM) reduced the frequency of synchronized Ca spikes among hippocampal neurons through the activation of CXCR4 by inhibiting cAMP pathways (Liu et al. 2003).

In the cerebellum (Fig. 1C), SDF-1 $\alpha$ induced calcium transient in cultured granule cells through a PTXresistant mechanism (Limatola et al. 2000). Purkinje neurons recorded in cerebellar slices in patch-clamp responded to SDF-1 $\alpha$ applications by an increase in spontaneous GABAergic activity and a slow inward current, which was drastically reduced by ionotropic glutamate receptor blockers. This current developed fully in a medium in which synaptic transmission was inhibited, suggesting that it was mediated by extrasynaptic glutamate, possibly released by surrounding glial and/or nerve cells. This current was followed by a rise in intracellular calcium sensitive to MCPG, thus mediated through metabotropic glutamate receptors, mGluRs (Limatola et al. 2000).

In rat SN (Fig. 1D), the CXCR4 receptor is expressed on both DA neurons and GABA axonal processes. Using whole-cell patch-clamp recordings in DA neurons of rat SN slices, we showed (Guyon et al. 2006 and unpublished data) that SDF-1 $\alpha$ exerts multiple pre- and postsynaptic effects on DA neurons, including (1) an increase in the frequency of spontaneous and miniature $\mathrm{GABA}_{\mathrm{A}}$ postsynaptic currents by presynaptic mechanisms, consistent with the presence of CXCR4 on GABAergic neurons of the $\mathrm{SN}$, as revealed by immunocytochemistry, (2) a glutamatergic inward current resistant to tetrodotoxine (TTX), likely due to glutamate release from nonneuronal cells; this inward current is not blocked by the CXCR4 antagonist AMD $3100(1 \mu \mathrm{M})$ consistent with the lack of CXCR4 on astrocytes under basal conditions as shown by immunocytochemistry, (3) an outward GIRK current, through CXCR4 activation, TTX sensitive, and prevented by the application of the $\mathrm{GABA}_{\mathrm{B}}$ antagonist CGP 55845A suggesting GABA spillover onto $\mathrm{GABA}_{\mathrm{B}}$ receptors, and (4) SDF- $1 \alpha(0 \cdot 1-10 \mathrm{nM})$ also increases the amplitude of total high voltage-activated calcium (HVA Ca) currents through CXCR4 activation. This effect was reversibly reduced by $\omega$-conotoxin GVIA, suggesting that SDF-1 $\alpha$ acted on N-type Ca currents, known to be mainly involved in DA release. However, at $100 \mathrm{nM}$, SDF-1 $\alpha$ inhibits $65 \%$ of HVA Ca currents by a CXCR4-independent mechanism. These effects of SDF-1 $\alpha$ on dopamine neuron activity were paralleled by modulations of dopamine release by DA neurons from the rat substantia 


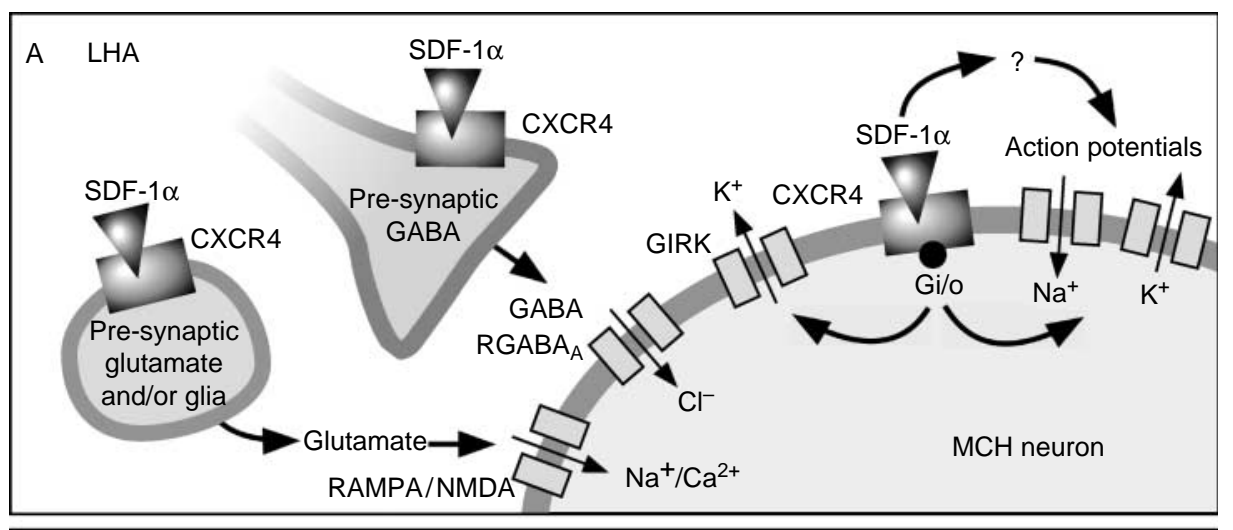

B Hippocampus
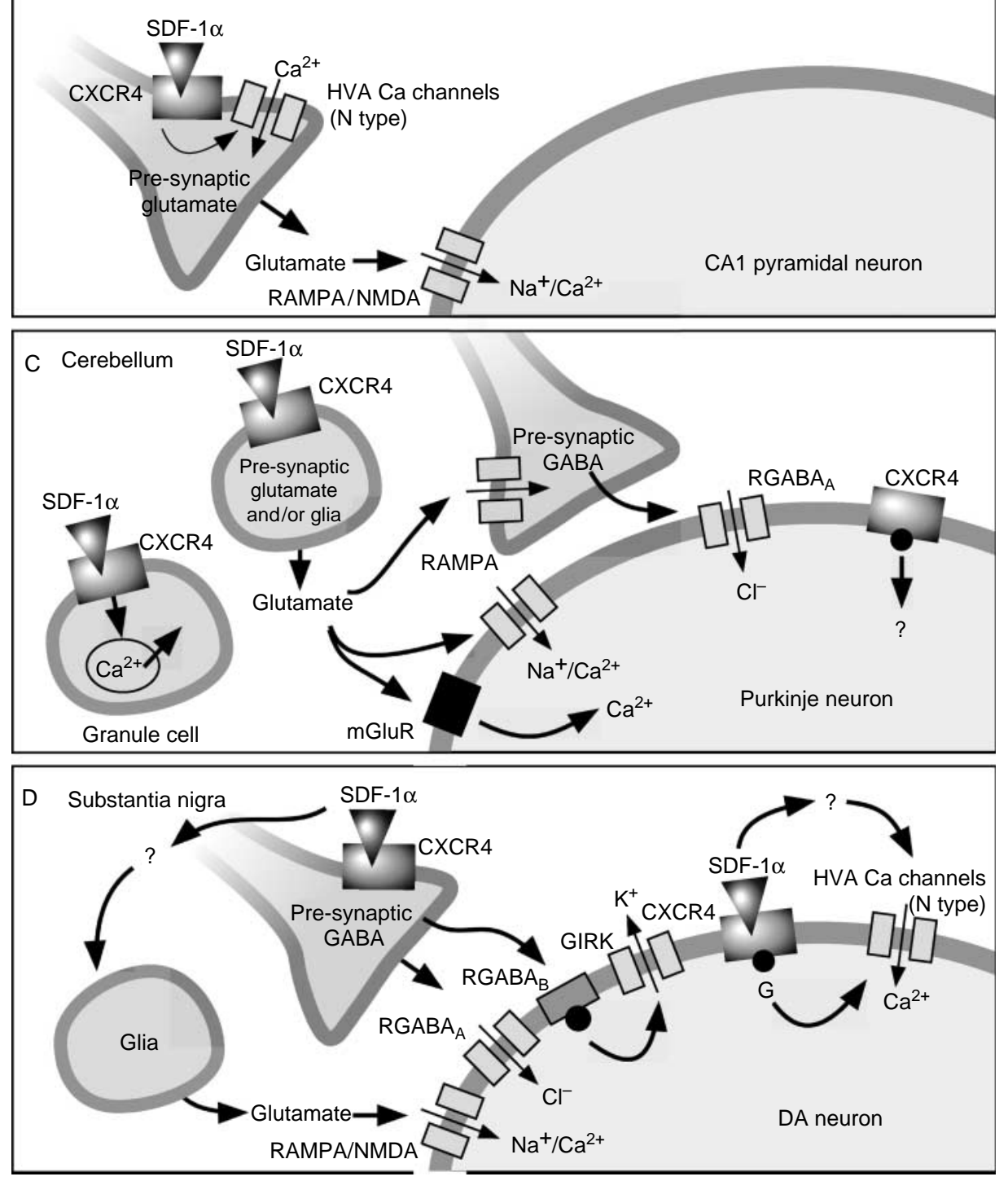
nigra, measured in preparations of dissociated neurons of rat mesencephalon as well as in vivo in the striatum, a projecting site of DA neurons, when SDF- $1 \alpha$ was injected in the SN (unpublished data of Patrick Kitabgi's team; U732 INSERM, Paris, France). These data strongly suggest that chemokines such as SDF- $1 \alpha$ can act as neuromodulators of DA neuronal activity.

It is interesting to note that SDF- $1 \alpha$ has convergent presynaptic actions in the different brain structures where it has been tested: it increases glutamate and/or GABA synaptic activities in lateral hypothalamus (Guyon et al. 2005b), hippocampus (Zheng et al. 1999), cerebellum (Limatola et al. 2000), and substantia nigra (Guyon et al. 2006). However, the presynaptic mechanisms of action of SDF- $1 \alpha$ vary from one structure to the other: for example, the increase in frequency of $\mathrm{GABA}_{\mathrm{A}}$ postsynaptic events in response to SDF-1 $\alpha$ occurs through an indirect mechanism involving glutamate in the cerebellum (Limatola et al. 2000), while the effect is direct through CXCR4 in the SN (Guyon et al. 2006). Similarly, the glutamate release is TTX dependent in the lateral hypothalamus (LHA) (Guyon et al. 2005b), while it is TTX independent in the SN (Guyon et al. 2006). The target effects on the postsynaptic neurons also vary depending on the structure. For example, the SDF-1 $\alpha$ increase in presynaptic GABA release in the LHA evokes a tonic $\mathrm{GABA}_{\mathrm{A}}$ current in $\mathrm{MCH}$-expressing neurons but does not induce GIRK current through $\mathrm{GABA}_{\mathrm{B}}$ receptors stimulation (Guyon et al. 2005b). This contrasts to what we found in DA neurons where no $\mathrm{GABA}_{\mathrm{A}}$ tonic current was induced by SDF- $1 \alpha$, but a GIRK current was activated through $\mathrm{GABA}_{\mathrm{B}} \mathrm{R}$ stimulation through a GABA spillover (Guyon et al. 2006). This could be due to various subunit compositions of the $\mathrm{GABA}_{\mathrm{A}}$ receptor expressed in the two neuronal populations, with different kinetics, and/or different subcellular localization of the $\mathrm{GABA}_{\mathrm{A} / \mathrm{B}} / \mathrm{CXCR} 4$ receptors and GIRK channels. Interestingly, in MCH neurons, SDF-1 $\alpha$ also induced the activation of a GIRK current, but this happened directly through CXCR4 stimulation. Finally, CXCR4 stimulation is able to modulate various voltagedependent channels: $\mathrm{Na}+$ and $\mathrm{K}+$ channels of the action potential in MCH neurons (Guyon et al. 2005b) and HVA Ca channels, in particular of the N-type, in DA neurons of the SN (A Guyon, unpublished data) and in presynaptic glutamatergic terminals of the hippocampus (Zheng et al. 1999).

In conclusion, from one structure to another, SDF-1 $\alpha$ has often similar consequences on neuronal transmembrane currents, but through different mechanisms.

\section{How can SDF-1 1 have opposite effects depending on the concentration?}

SDF-1 $\alpha$ often appears to have opposite effects on neuronal function depending on the concentration. For example, in DA neurons, at low concentrations, it acts as a neuromodulator by potentiating $\mathrm{K}+$-induced DA secretion and HVA calcium currents, whereas at higher concentration, it decreases DA release and HVA calcium currents. This can be paralleled to what happens in $\mathrm{MCH}$ neurons of the lateral hypothalamus, where SDF- $1 \alpha$ also exerts opposite effects on the action potential discharge depending on the concentration (Guyon et al. 2005b). Moreover, this can also be observed in other contexts, for example, low levels of SDF-1 $(<100 \mathrm{ng} / \mathrm{ml})$ are attractive, whereas higher levels $(>1 \mu \mathrm{g} / \mathrm{ml})$ are repulsive for T cells (Zlatopolskiy $\&$ Laurence 2001). Several putative mechanisms for these opposite effects, which are not mutually exclusive, are reviewed in Fig. 3.

\section{Two affinity sites on the CXCR4 receptor?}

SDF-1 $\alpha$ interactions with its receptor CXCR4 occur at two binding sites in amino acids $1-17$ of SDF-1 $\alpha$ (Crump et al. 1997). The initial step involves a 'docking site' on SDF- $1 \alpha$ (amino acids 12-17) in the N-terminus of CXCR4 (amino acids 10-21). Subsequently, residues 1-9 of SDF-1 $\alpha$ bind to another region within CXCR4. Although the signal appears to be transduced only when this 'signaling site' is bound, the occupation of

Figure 1 Different effects of SDF- $1 \alpha$ in various brain structures. (A) In the LHA, SDF-1 $\alpha$ increases spontaneous presynaptic glutamate and GABA release. Moreover, CXCR4 stimulation activates a GIRK current in MCH neurons. SDF-1 $\alpha$ also modulates the action potential discharge of these neurons through a modulation of voltage-gated sodium current and delayed rectifier-potassium current (Guyon et al. $2005 a, b)$. (B) SDF-1 $\alpha$ induces an enhancement of excitatory synaptic transmission in rat hippocampus through CXCR4 and N-type calcium channel-dependent mechanism (Zheng et al. 1999). (C) In granule cells of the cerebellum, CXCR4 activation by SDF-1 $\alpha$ induces calcium transient. In Purkinje neurons, although they express CXCR4, SDF-1 $\alpha$ effects are mediated through extrasynaptic glutamate, possibly released by surrounding glial and/or nerve cells. Glutamate induces a slow inward current, 6-cyano-7 nitroquinoxaline-2,3 dione (CNQX) sensitive, thus involving the non- $N$-methyl $D$ aspartate (non-NMDA) ionotropic glutamate receptors. This is followed by a rise in intracellular calcium sensitive to MCPG, thus mediated through metabotropic glutamate receptors, mGluRs (Limatola et al. 2000). (D) In rat substantia nigra (SN), SDF-1 $\alpha$ increases the frequency of spontaneous and miniature GABA $A_{A}$ postsynaptic currents by presynaptic mechanisms. It also induces a glutamatergic inward current resistant to TTX, likely due to glutamate release from non-neuronal cells. On DA neurons, SDF-1 $\alpha$ activates an outward GIRK current, through CXCR4 presynaptic activation and GABA spillover onto GABA $\mathrm{G}_{\mathrm{B}}$ receptors (Guyon et al. 2006). SDF-1 $\alpha(0 \cdot 1-10 \mathrm{nM})$ also increases the amplitude of total high voltage-activated calcium (HVA Ca) currents through CXCR4 activation. However, at $100 \mathrm{nM}$, SDF- $1 \alpha$ inhibits $65 \%$ of HVA Ca currents by a CXCR4-independent mechanism. 


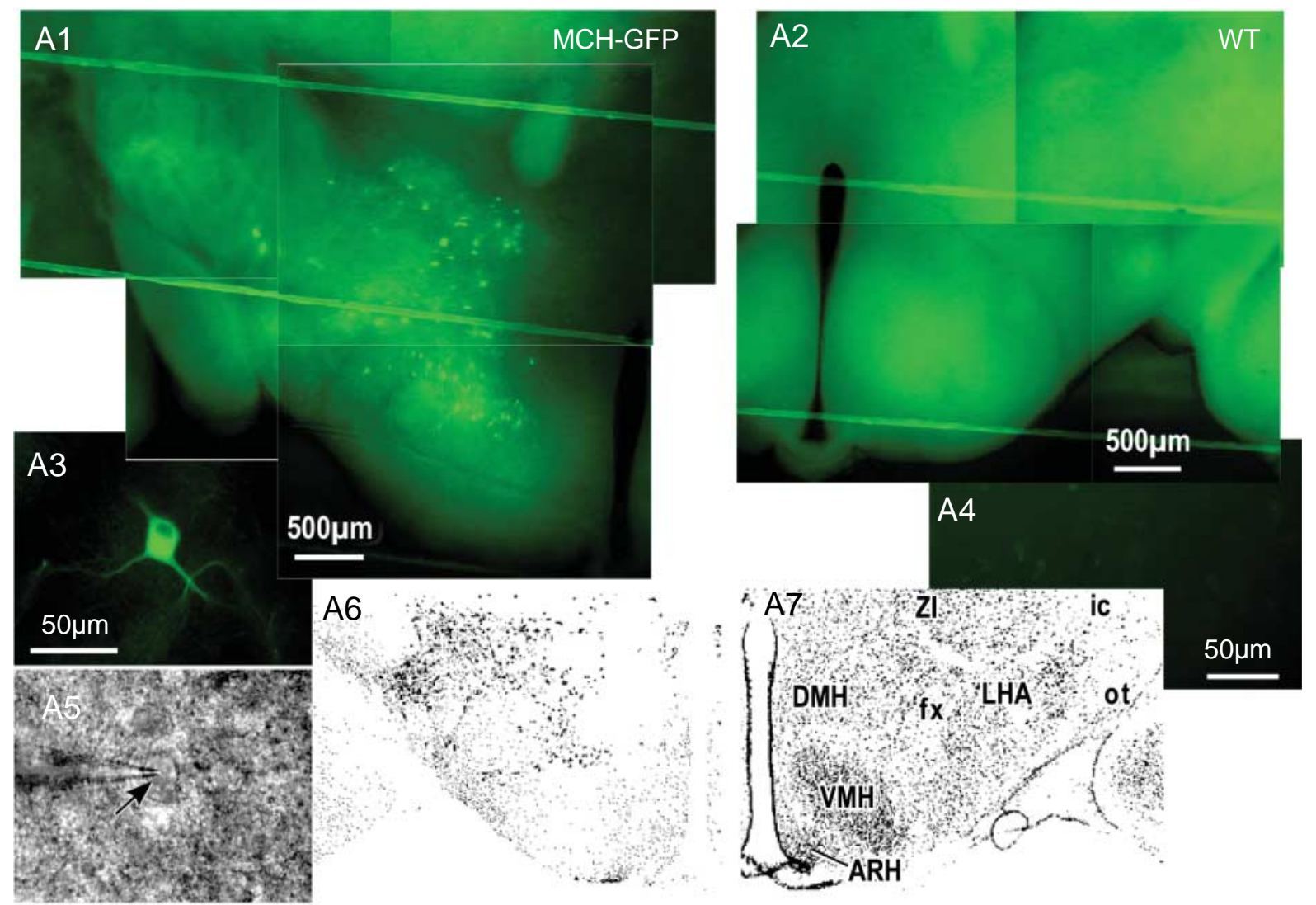

B1

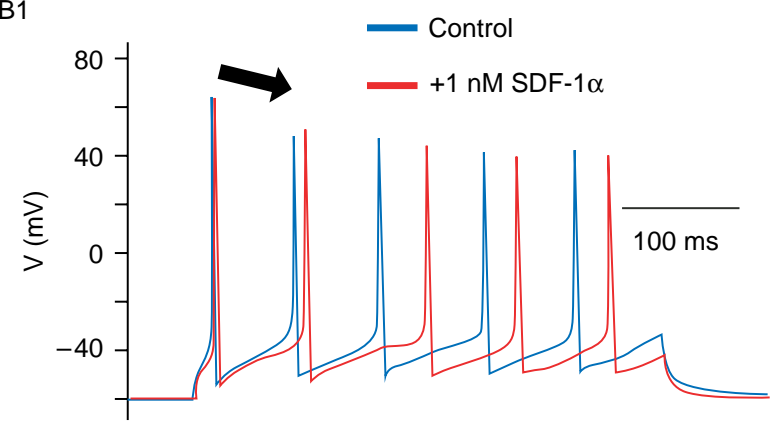

B2

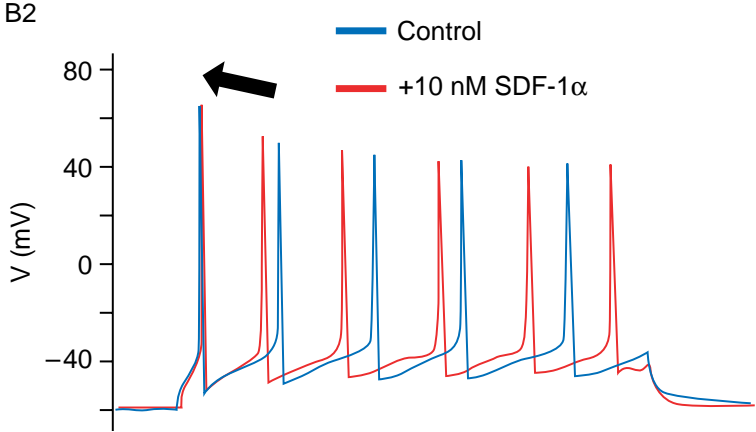

Figure 2 Opposite concentration-dependent effects of SDF-1 $\alpha$ on the action potential discharge of MCH neurons of transgenic MCH-GFP mice. At the top are presented reconstructed transversal $250 \mu \mathrm{m}$ thick hypothalamic sections obtained from a 15-day-old transgenic mouse in which GFP is under the control of $\mathrm{MCH}$ promoter (MCH-GFP, A1). Notice the MCH neurons detected as green fluorescence and their absence in wild-type (WT) mouse (A2). A3 shows GFP fluorescence of a MCH neuron at a higher magnification when compared with background noise in WT mouse (A4). The same neuron as in A3 is presented in A5 by infrared-differential interference contrast (IR-DIC) microscopy (arrowhead on the recording electrode tip). A6 is an immunostained section of the lateral hypothalamus at P15 obtained with an anti-MCH antibody. Note that the distribution of $\mathrm{MCH}$ neurons is similar to that in $\mathrm{A} 1$. A7 is a Nissl staining of a hypothalamic slice at the same anteroposterior level, showing the different structures: $\mathrm{ARH}$, arcuate nucleus; $\mathrm{DMH}$, dorsomedian hypothalamus; $\mathrm{fx}$, fornix; ic, internal capsule; LHA, lateral hypothalamus; ot, optic tract; VMH, ventromedian hypothalamus; ZI, zona incerta. (B) Whole-cell patchclamp recordings in the current-clamp mode of $\mathrm{MCH}$-GFP fluorescent neurons. At a low concentration (1 nM, B1), SDF-1 $\alpha$ decreases the frequency of action potential discharge, whereas at a higher concentration (10 nM, B2), SDF-1 $\alpha$ does the opposite.

one or two sites of the CXCR4, depending on the concentration, could activate different signaling pathways. Desensitization and internalization at the highest SDF- $1 \alpha$ concentrations could also be involved (Fig. 3A).

\section{Homo-heterodimerization?}

Following SDF-1 $\alpha$ interaction, CXCR4 undergoes a dimerization which is necessary for its functionality and signaling (Mellado et al. 2001, Toth et al. 2004). 
A

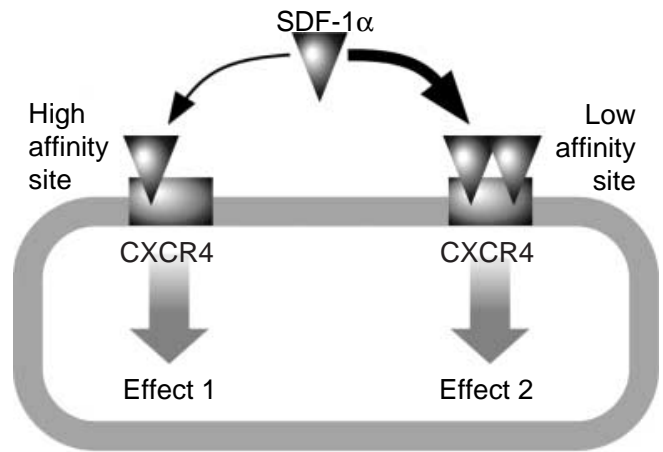

B

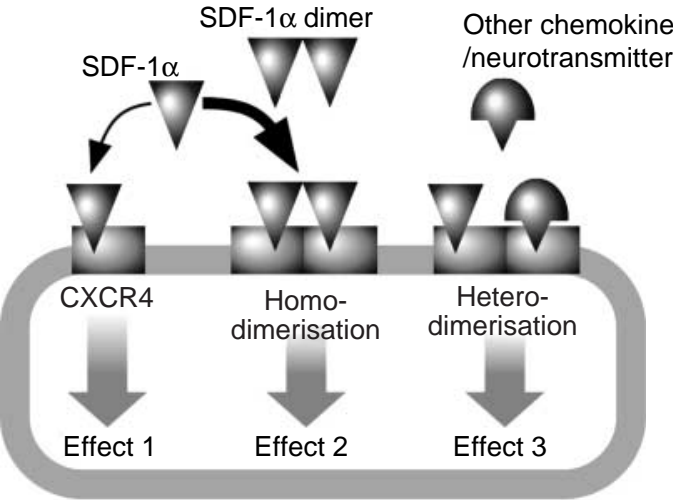

C

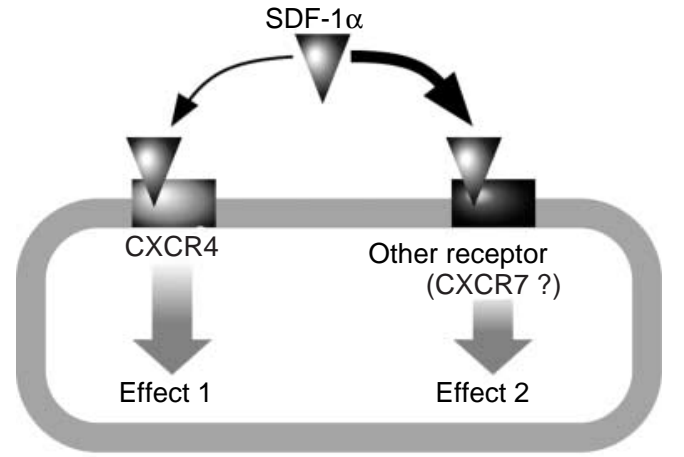

D

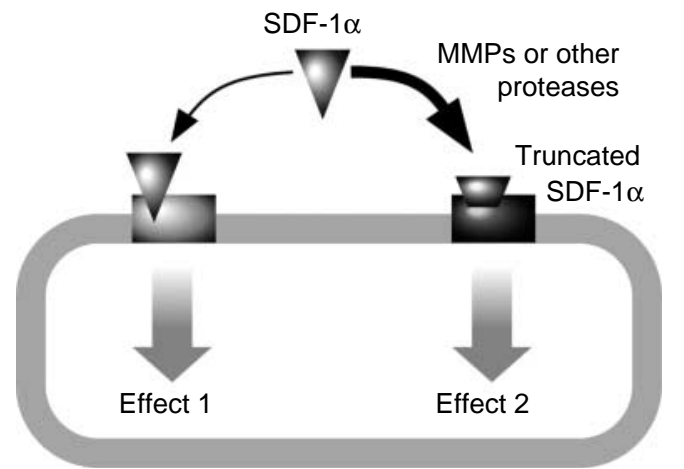

Dimerization is accompanied by receptor phosphorylation as well as changes in signal transduction processes (Rodriguez-Frade et al. 2001). This dimerization enables the activation of the JAK/STAT pathway, which allows the subsequent triggering of G-proteindependent signaling events (Vila-Coro et al. 1999; (Fig. 3B)).

Furthermore, SDF-1 $\alpha$ itself can form a dimeric structure in solution at non-acidic $\mathrm{pH}$. This dimerization has been shown to be stabilized by glycosaminoglycan, and heparin-mediated oligomerization may be essential for signaling (Sadir et al. 2001, Veldkamp et al. 2005). It is therefore possible that, depending on the concentration, SDF- $1 \alpha$ would act as a monomer or oligomer on CXCR4 monomers or homodimers, leading to different responses. Heterodimerization is known to play a role in signal transduction of other metabotropic receptors, for example, $\mathrm{GABA}_{\mathrm{B}}$ receptors interact with metabotropic glutamate receptors (Hirono et al. 2001). CXCR4 could also form heterodimers with other GPCRs, which could lead to complex responses according to the chemokines/ peptides/neuromediator environment present in the extracellular medium. Indeed, we have preliminary data suggesting that CXCR4 should interact with GABA $_{B}$ receptors. As SDF-1 $\alpha$ influences presynaptic GABA release, this could be another way to explain how different SDF-1 $\alpha$ concentrations lead to different effects. Furthermore, CXCR4 and CCR2 (the receptor for the chemokine MCP-1) are co-expressed in DA neurons of the SN. As they have been shown to form heterodimers (Percherancier et al. 2005), we are currently investigating whether SDF-1 $\alpha$ and MCP-1 can exert synergistic effects on DA neuron activity.

\section{Action on receptors other than CXCR4?}

It is not excluded that SDF-1 $\alpha$ at high concentrations could act on a receptor other than CXCR4 to exert its actions. This could explain why, in $\mathrm{MCH}$ and DA neurons, the effects of high concentrations of SDF-1 $\alpha$ were not blocked by the selective CXCR4 antagonist AMD 3100 at concentrations up to $1 \mu \mathrm{M}$. Indeed, the $\mathrm{T}$

Figure 3 Putative mechanisms of the opposite effects of SDF- $1 \alpha$ at low and high concentrations. (A) Depending on the concentration, SDF- $1 \alpha$ could bind only to the high-affinity site or to both high- and low-affinity sites, leading to distinct responses. (B) CXCR4 could induce different responses as monomer, homodimer, or heterodimer. The formation of the various complexes could depend on SDF- $1 \alpha$ concentration (and on its dimerization), but also probably on other factors, such as the CXCR4 phosphorylation/internalization, the local concentration of heparane sulfate, and/or some synergistic transmitters/GPCRs. (C) SDF- $1 \alpha$ could bind to another receptor than CXCR4, leading to a distinct response. (D) SDF-1 $\alpha$ cleaved by several proteases could lead to active peptides that would induce other responses than intact SDF- $1 \alpha$. 
lymphocytes orphan receptor, RDC1, just described as a new receptor for SDF- $1 \alpha$ and named CXCR7 (Balabanian et al. 2005) has been reported in tumor endothelial cells of the brain (Madden et al. 2004), but no data are available in the normal brain (Fig. 3C).

\section{Actions of SDF-1 $\alpha$ metabolites?}

Peptide metabolites can be active in other systems. For example, AVP fragments have a biological activity distinct from intact peptide (Stoehr et al. 1992, Fujiwara et al. 1997). This should also be the case for SDF- $1 \alpha$. SDF- $1 \alpha$ can be cleaved by several enzymes, leading to peptides inactive on CXCR4. For example, dipeptidyl peptidase IV (DPP IV) cleaves the peptide into SDF-1 (3-68) product (Proost et al. 1998, Mentlein 1999), leukocyte elastase into SDF-1 (4-67) (ValenzuelaFernandez et al. 2002), matrix metalloprotease (MMP)-2 into SDF-1 (5-67) (Zhang et al. 2003), and cathepsin G into SDF-1 (6-67) (Delgado et al. 2001); all proteolyzed fragments becoming inactive on CXCR4. Interestingly, leukocyte elastase also inactivates CXCR4 (Valenzuela-Fernandez et al. 2002). It is worth noting that the enzymes are often carried or secreted by cells attracted by SDF- $1 \alpha$. In the case of MMP-2, pro-MMP-2 is produced by macrophages and activated by neuronal MT1-MPP (Zhang et al. 2003). Furthermore, CXCR4 activation by SDF-1 $\alpha$ itself has been shown to increase the secretion of MMPs (Klier et al. 2001). Thus, it appears that there may be a feedback process inactivating SDF- $1 \alpha$ once the target cells have reached the site of infection. On the other hand, the peptide SDF- $1 \alpha$ can be protected from DPPs cleavage by its binding with heparane sulfate present on cell membranes, which would result in concentrating it locally (Amara et al. 1999, Sadir et al. 2004). Among the metabolites of SDF-1 $\alpha$, some may have physiological effects. Indeed, SDF-1 (5-67) implanted into the basal ganglia of mice can produce neuronal death and inflammation, and its actions are mediated through a G-protein-coupled receptor, as yet unidentified (Zhang et al. 2003). It is therefore possible that the opposite effects observed on neuronal activity at higher SDF- $1 \alpha$ concentrations could come from a cleavage of SDF- $1 \alpha$ by enzymes when heparan sulfate sites have been saturated. The possibility that other SDF-1 metabolites could affect neuronal activity/survival will have to be investigated by enzyme blockers or by applying the cleaved peptides directly (Fig. 3D).

\section{Physiopathological considerations}

The fact that SDF- $1 \alpha$ and its receptor CXCR4 are expressed in the same or interrelated neuronal populations suggests that SDF- $1 \alpha$ could act as a neuromodulator and exert a tonic action on neurons. For instance, low concentrations of SDF- $1 \propto$ could exert a tonic inhibition on MCH neurons, which are known to have a hyperpolarized membrane potential in basal conditions, when compared with orexin neurons of the LHA, which are in an intrinsic state of membrane depolarization (Eggermann et al. 2003). In addition, the CXCR4 antagonist AMD 3100 has its own effects when applied alone, which suggests that a tonic activation of CXCR4 occurs, at least in slices preparations, and that low levels of SDF- $1 \alpha$ are secreted under basal conditions. However, the slice preparation, in which the cells have been stressed, could also be considered as an inflammatory state (Fig. 4).

Inflammation is often accompanied with anorexia, but the mechanisms underlying this phenomenon are poorly understood (Plata-Salaman 2001). One of the pathways could involve $\mathrm{MCH}$ neurons. Indeed, the following acute injections of lipopoly saccharide (LPS) in mice, which induce an inflammatory response, there is a decrease in the expression of MCH mRNAs (Sergeyev et al. 2001). A decrease in $\mathrm{MCH}$ release from MCH neurons of the LHA could lead to anorexia. Following inflammation, cytokines are released in the blood and they can reach the brain, the blood-brain barrier permeability being increased. Cytokine stimulation could lead to higher levels of SDF- $1 \alpha$ by activation of glial or endothelial cells that release chemokines (Meucci et al. 1998, Ohtani et al. 1998, Lee et al. 2002). The released SDF$1 \alpha$ could reach MCH neurons, bind CXCR4, and induce a change in the excitability of the neurons that could induce an adaptive answer to the inflammation and anorexia. One can also imagine that a prolonged inflammation, leading to higher levels of SDF-1 $\alpha$, could lead to neurotoxicity through one or several of the mechanisms described in Fig. 3, and to neurodegenerescence. In this context, chronic LPS injections lead to a decrease in the number of MCH neurons (Gerashchenko \& Shiromani 2004).

Similarly, SDF- $1 \alpha$ could exert autocrine effects on vasopressinergic neurons, since the chemokine as well as its receptor are present in these neurons. The known autoregulation of AVP on its own neurons and its control by apelin which is co-expressed with its receptors in these cells (De Mota et al. 2004), could be accompanied by a third autocrine system mediated by SDF-1 $\alpha$. SDF-1 $\alpha$ could therefore affect the neuroendocrine circuits controlling drinking as well as feeding behaviors. We have preliminary data that sustain such hypothesis in the LHA (K Palin and F Moss, personal communication). It will be interesting to determine whether this is a particularity of AVP (and $\mathrm{MCH}$ ) neurons or if most neuroendocrine cells express modulators and their receptors. 


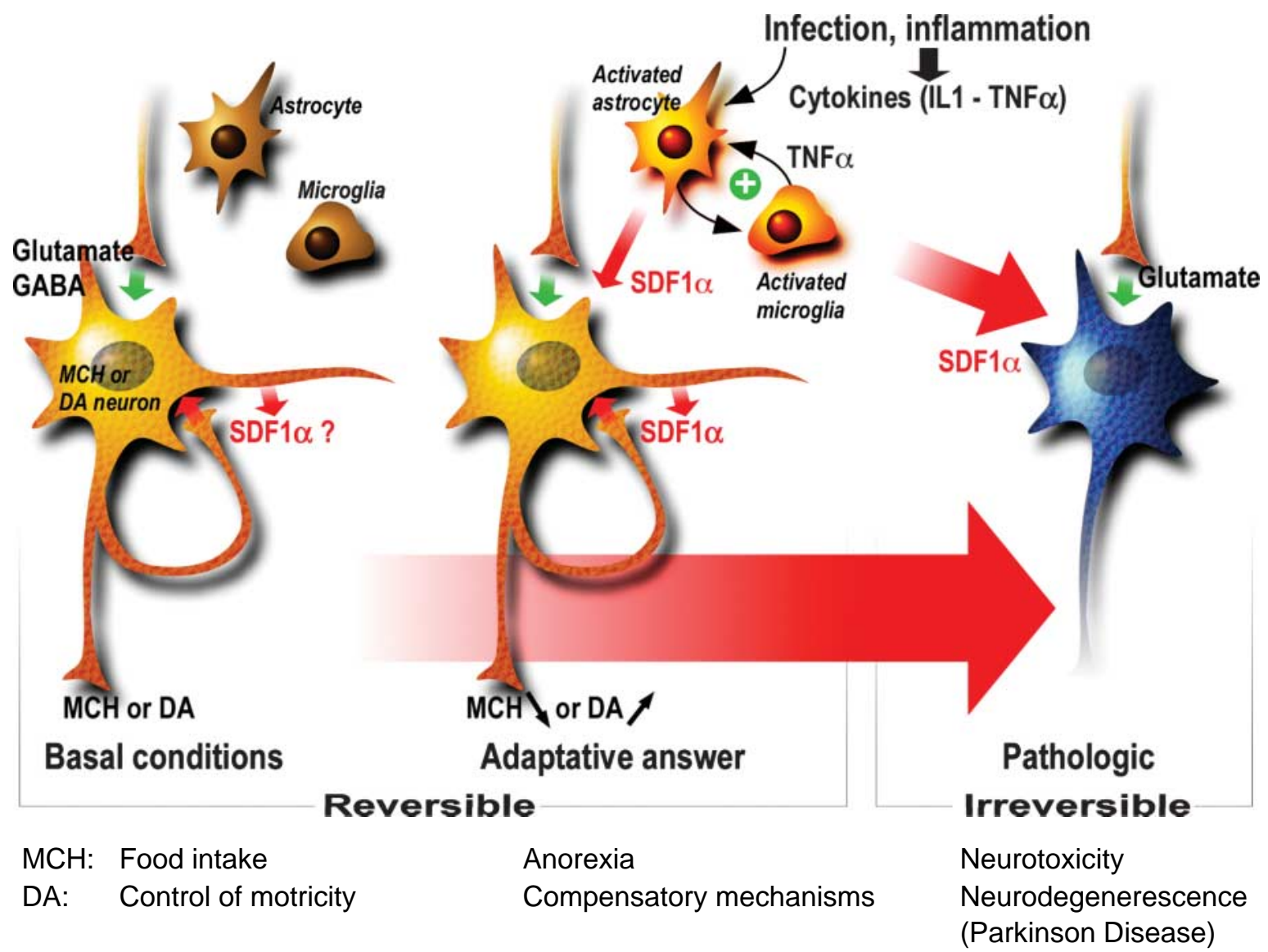

Figure 4 Physiopathological consequences of the effects of SDF-1 $\alpha$ in two neuronal populations: the MCH neurons of the LHA and the DA neurons of the substantia nigra. SDF-1 $\alpha$ released by axon collaterals or somato-dendritic structures (particularly in the case of the substantia nigra; Ludwig \& Pittman 2003) could exert a tonic effect on MCH and DA neurons in basal conditions (left). In the case of an acute infection or inflammation, following activation of glial cells and/or vascular SDF- $1 \alpha$ transport, the SDF- $1 \alpha$ concentration increases and other factors such as glutamate are secreted. By modifying the firing pattern of neurons, SDF-1 $\alpha$ leads to neuronal and behavioral adaptive changes: decreased $\mathrm{MCH}$ release and anorexia, and increased DA release and compensatory mechanisms during asymptomatic steps of Parkinson disease (middle). When the SDF-1 $\alpha$ concentrations reach a certain threshold, when SDF-1 $\alpha$ exposure is prolonged in time or when SDF-1 $\alpha$ is associated to other factors or cleaved in metabolites, it could have irreversible consequences, such as neurodegenerescence (right).

Parkinson's disease is one of the most prevalent neurodegenerative disorders and is characterized by the progressive loss of DA neurons in the SN. In the presymptomatic states of the disease, the remaining DA neurons can compensate for the loss of DA neurons by increasing their activity (Zigmond 1997). There is increasing evidence to suggest that the brain inflammatory response contributes to Parkinson's disease pathogenesis (Kurkowska-Jastrzebska et al. 1999, Cicchetti et al. 2002). The loss of these neurons is associated with a glial response composed mainly of activated microglial cells and, to a lesser extent, of reactive astrocytes (Liberatore et al. 1999, Vila et al. 2001). This glial response may be the source of tropic factors that can protect against reactive oxygen species and glutamate. As we proposed in our and Patrick
Kitabgi's team studies, chemokines such as SDF-1 $\alpha$ by increasing DA release could also participate to promote compensatory mechanisms of remaining DA neurons at the early stages of the pathology. Apart from these beneficial effects, the glial response under chronic conditions can mediate a variety of deleterious events related to the production of reactive species, and proinflammatory prostaglandin and cytokines (Vila et al. 2001). In this context, it was recently reported that SDF- $1 \alpha$ expression was markedly increased in the reactive astrocytes in the $\mathrm{SN}$ of rat treated with 6-hydroxydopamine, a neurotoxin that induces selective destruction of central DA neurons (E Apartis Communication at the 7 th French Neuroscience Society meeting, Lille, France 2005). This could represent a novel pathway associated with the induction 
of DA neuronal death in Parkinson's disease, possibly through enhanced release of SDF- $1 \alpha$ and production of SDF-1 $\alpha(5-67)$ in the SN. Overall, these results call for further investigations into the role of chemokines, such as SDF- $1 \alpha$ on the activity and survival of DA neurons under normal and pathological conditions. Agents acting on CXCR4 (Heveker et al. 2001) could thus represent useful agents in neurodegenerative diseases involving neuroinflammatory disorders, such as multiple sclerosis, Alzheimer's disease, Parkinson's disease, and HIV-associated dementia.

\section{General conclusion}

Convergent data suggest that SDF- $1 \alpha$ could act in the central nervous system as a classical neuromediator under normal conditions and could modulate the activity of several neuroendocrine networks. However, during a pathological state (altered immune response or inflammation), abnormal concentrations of SDF- $1 \alpha$ and/or its presence at unusual sites can be found, due to its local production by glial and/or endothelial cells and/or its diffusion and transportation through the vascular circulation. This enhanced production of SDF- $1 \alpha$ could affect neuronal and neuroendocrine activities and modify the functioning of the brain, leading to pathological behaviors and/or neurotoxicity.

\section{Acknowledgements}

We thank very much Dr Shirly Pinto and Agnès Viale, and Prof. Jeffrey Friedman (The Rockefeller University, New York, NY, USA) for kindly providing GFP-MCH transgenic mice. We also thank the group of Patrick Kitabgi for excellent advice and very constructive collaboration. We are grateful to Corinne Panek and Jean-Daniel Barde for animal care, Carole Rovère and Natacha Grand for screening and genotyping the animals, and Franck Aguila for excellent artwork assistance. This work was supported by the Association pour la Recherche sur le Cancer (ARC; subvention 3375), the Fondation de France (Comité Parkinson), and the Centre National de la Recherche Scientifique (in part Programme OHLL-2002/2004). The authors declare that there is no conflict of interest that would prejudice the impartiality of this scientific work.

\section{References}

Amara A, Lorthioir O, Valenzuela A, Magerus A, Thelen M, Montes M, Virelizier JL, Delepierre M, Baleux F, Lortat-Jacob H et al. 1999 Stromal cell-derived factor-1alpha associates with heparan sulfates through the first beta-strand of the chemokine. Journal of Biological Chemistry 274 23916-23925.
Bacon KB \& Harrison JK 2000 Chemokines and their receptors in neurobiology: perspectives in physiology and homeostasis. Journal of Neuroimmunology 104 92-97.

Bajetto A, Bonavia R, Barbero S, Piccioli P, Costa A, Florio T \& Schettini G 1999 Glial and neuronal cells express functional chemokine receptor CXCR4 and its natural ligand stromal cellderived factor 1. Journal of Neurochemistry 73 2348-2357.

Bajetto A, Bonavia R, Barbero S, Florio T \& Schettini G $2001 a$ Chemokines and their receptors in the central nervous system. Frontiers in Neuroendocrinology 22 147-184.

Bajetto A, Barbero S, Bonavia R, Piccioli P, Pirani P, Florio T \& Schettini G $2001 b$ Stromal cell-derived factor-lalpha induces astrocyte proliferation through the activation of extracellular signal-regulated kinases 1/2 pathway. Journal of Neurochemistry 77 1226-1236.

Balabanian K, Lagane B, Infantino S, Chow KY, Harriague J, Moepps B, Arenzana-Seisdedos F, Thelen M \& Bachelerie F 2005 The chemokine SDF-1/CXCL12 binds to and signals through the orphan receptor RDC1 in T lymphocytes. Journal of Biological Chemistry 280 35760-35766.

Banisadr G, Fontanges P, Haour F, Kitabgi P, Rostene W \& Melik Parsadaniantz S 2002 Neuroanatomical distribution of CXCR4 in adult rat brain and its localization in cholinergic and dopaminergic neurons. European Journal of Neuroscience 16 1661-1671.

Banisadr G, Skrzydelski D, Kitabgi P, Rostene W \& Parsadaniantz SM 2003 Highly regionalized distribution of stromal cell-derived factor-1/CXCL12 in adult rat brain: constitutive expression in cholinergic, dopaminergic and vasopressinergic neurons. European Journal of Neuroscience 18 1593-1606.

Banisadr G, Rostene W, Kitabgi P \& Parsadaniantz SM 2005a Chemokines and brain functions. Current Drug Targets. Inflammation and Allergy 4 387-399.

Banisadr G, Gosselin RD, Mechighel P, Kitabgi P, Rostene W \& Parsadaniantz SM 2005b Highly regionalized neuronal expression of monocyte chemoattractant protein-1 (MCP-1/CCL2) in rat brain: evidence for its colocalization with neurotransmitters and neuropeptides. Journal of Comparative Neurology 489 275-292.

Bonavia R, Bajetto A, Barbero S, Pirani P, Florio T \& Schettini G 2003 Chemokines and their receptors in the CNS: expression of CXCL12/SDF-1 and CXCR4 and their role in astrocyte proliferation. Toxicology Letters 139 181-189.

Callewaere C, Banisadr G, Desarmenien MG, Mechighel P, Kitabgi P, Rostene WH \& Melik Parsadaniantz S 2006 The chemokine SDF-1/CXCL12 modulates the firing pattern of vasopressin neurons and counteracts induced vasopressin release through CXCR4. PNAS 103 8221-8226.

Cartier L, Hartley O, Dubois-Dauphin M \& Krause KH 2005 Chemokine receptors in the central nervous system: role in brain inflammation and neurodegenerative diseases. Brain Research. Brain Research Reviews 48 16-42.

Chalasani SH, Sabelko KA, Sunshine MJ, Littman DR \& Raper JA $2003 a$ A chemokine, SDF-1, reduces the effectiveness of multiple axonal repellents and is required for normal axon pathfinding. Journal of Neuroscience 23 1360-1371.

Chalasani SH, Baribaud F, Coughlan CM, Sunshine MJ, Lee VM, Doms RW, Littman DR \& Raper JA $2003 b$ The chemokine stromal cellderived factor-1 promotes the survival of embryonic retinal ganglion cells. Journal of Neuroscience 23 4601-4612.

Cicchetti F, Brownell AL, Williams K, Chen YI, Livni E \& Isacson O 2002 Neuroinflammation of the nigrostriatal pathway during progressive 6-OHDA dopamine degeneration in rats monitored by immunohistochemistry and PET imaging. European Journal of Neuroscience 15 991-998.

Crump MP, Gong JH, Loetscher P, Rajarathnam K, Amara A, ArenzanaSeisdedos F, Virelizier JL, Baggiolini M, Sykes BD \& Clark-Lewis I 1997 Solution structure and basis for functional activity of stromal cell-derived factor-1; dissociation of CXCR4 activation from binding and inhibition of HIV-1. EMBO Journal 16 6996-7007. 
Delgado MB, Clark-Lewis I, Loetscher P, Langen H, Thelen M, Baggiolini M \& Wolf M 2001 Rapid inactivation of stromal cellderived factor-1 by cathepsin $\mathrm{G}$ associated with lymphocytes. European Journal of Immunology 31 699-707.

De Mota N, Reaux-Le Goazigo A, El Messari S, Chartrel N, Roesch D, Dujardin C, Kordon C, Vaudry H, Moos F \& Llorens-Cortes C 2004 Apelin, a potent diuretic neuropeptide counteracting vasopressin actions through inhibition of vasopressin neuron activity and vasopressin release. PNAS 101 10464-10469.

Doranz BJ, Berson JF, Rucker J \& Doms RW 1997 Chemokine receptors as fusion cofactors for human immunodeficiency virus type 1 (HIV-1). Immunologic Research 16 15-28.

Eggermann E, Bayer L, Serafin M, Saint-Mleux B, Bernheim L, Machard D, Jones BE \& Muhlethaler M 2003 The wake-promoting hypocretin-orexin neurons are in an intrinsic state of membrane depolarization. Journal of Neuroscience 23 1557-1562.

Feng Y, Broder CC, Kennedy PE \& Berger EA 1996 HIV-1 entry cofactor: functional cDNA cloning of a seven-transmembrane, G protein-coupled receptor. Science 272 872-877.

Fujiwara M, Ohgami Y, Inada K \& Iwasaki K 1997 Effect of active fragments of arginine-vasopressin on the disturbance of spatial cognition in rats. Behavioural Brain Research 83 91-96.

Gerashchenko D \& Shiromani PJ 2004 Effects of inflammation produced by chronic lipopolysaccharide administration on the survival of hypocretin neurons and sleep. Brain Research 1019 162-169.

Glabinski AR \& Ransohoff RM 1999 Sentries at the gate: chemokines and the blood-brain barrier. Journal of Neurovirology 5 623-634.

Gleichmann M, Gillen C, Czardybon M, Bosse F, Greiner-Petter R, Auer J \& Muller HW 2000 Cloning and characterization of SDF-1gamma, a novel SDF-1 chemokine transcript with developmentally regulated expression in the nervous system. European Journal of Neuroscience 12 1857-1866.

Guyon A, Rovere C, Cervantes A, Allaeys I \& Nahon JL 2005a Stromal cell-derived factor-1alpha directly modulates voltage-dependent currents of the action potential in mammalian neuronal cells. Journal of Neurochemistry 93 963-973.

Guyon A, Banisadr G, Rovere C, Cervantes A, Kitabgi P, MelikParsadaniantz S \& Nahon JL 2005 $b$ Complex effects of stromal cellderived factor-lalpha on melanin-concentrating hormone neuron excitability. European Journal of Neuroscience 21 701-710.

Guyon A, Skrzydelsi D, Rovere C, Rostene W, Parsadaniantz SM \& Nahon JL 2006 Stromal cell-derived factor-1alpha modulation of the excitability of rat substantia nigra dopaminergic neurones: presynaptic mechanisms. Journal of Neurochemistry 96 1540-1550.

Haribabu B, Richardson RM, Fisher I, Sozzani S, Peiper SC, Horuk R, Ali H \& Snyderman R 1997 Regulation of human chemokine receptors CXCR4. Role of phosphorylation in desensitization and internalization. Journal of Biological Chemistry 272 28726-28731.

Heveker N, Tissot M, Thuret A, Schneider-Mergener J, Alizon M, Roch M \& Marullo S 2001 Pharmacological properties of peptides derived from stromal cell-derived factor 1: study on human polymorphonuclear cells. Molecular Pharmacology 59 1418-1425.

Hirono M, Yoshioka T \& Konishi S 2001 GABA(B) receptor activation enhances mGluR-mediated responses at cerebellar excitatory synapses. Nature Neuroscience 4 1207-1216.

Huising MO, Stet RJ, Kruiswijk CP, Savelkoul HF \& Lidy Verburg-van Kemenade BM 2003 Molecular evolution of CXC chemokines: extant CXC chemokines originate from the CNS. Trends in Immunology 24 307-313.

Kaul M \& Lipton SA 2004 Signaling pathways to neuronal damage and apoptosis in human immunodeficiency virus type 1-associated dementia: chemokine receptors, excitotoxicity, and beyond Journal of Neurovirology 10 97-101.

Khan MZ, Brandimarti R, Patel JP, Huynh N, Wang J, Huang Z, Fatatis A \& Meucci O 2004 Apoptotic and antiapoptotic effects of CXCR4: is it a matter of intrinsic efficacy? Implications for HIV neuropathogenesis. AIDS Research and Human Retroviruses 20 1063-1071.
Klein RS, Williams KC, Alvarez-Hernandez X, Westmoreland S, Force T, Lackner AA \& Luster AD 1999 Chemokine receptor expression and signaling in macaque and human fetal neurons and astrocytes: implications for the neuropathogenesis of AIDS. Journal of Immunology 163 1636-1646.

Klier CM, Nelson EL, Cohen CD, Horuk R, Schlondorff D \& Nelson PJ 2001 Chemokine-induced secretion of gelatinase B in primary human monocytes. Biological Chemistry 382 1405-1410.

Kurkowska-Jastrzebska I, Wronska A, Kohutnicka M, Czlonkowski A \& Czlonkowska A 1999 The inflammatory reaction following 1-methyl4-phenyl-1,2,3, 6-tetrahydropyridine intoxication in mouse. Experimental Neurology 156 50-61.

Lazarini F, Casanova P, Tham TN, De Clercq E, Arenzana-Seisdedos F, Baleux F \& Dubois-Dalcq M 2000 Differential signalling of the chemokine receptor CXCR4 by stromal cell-derived factor 1 and the HIV glycoprotein in rat neurons and astrocytes. European Journal of Neuroscience 12 117-125.

Lazarini F, Tham TN, Casanova P, Arenzana-Seisdedos F \& DuboisDalcq M 2003 Role of the alpha-chemokine stromal cell-derived factor (SDF-1) in the developing and mature central nervous system. Glia 42 139-148.

Lee YB, Nagai A \& Kim SU 2002 Cytokines, chemokines, and cytokine receptors in human microglia. Journal of Neuroscience Research 69 94-103.

Liberatore GT, Jackson-Lewis V, Vukosavic S, Mandir AS, Vila M, McAuliffe WG, Dawson VL, Dawson TM \& Przedborski S 1999 Inducible nitric oxide synthase stimulates dopaminergic neurodegeneration in the MPTP model of Parkinson disease. Nature Medicine 5 1403-1409.

Limatola C, Giovannelli A, Maggi L, Ragozzino D, Castellani L, Ciotti MT, Vacca F, Mercanti D, Santoni A \& Eusebi F 2000 SDF-1alphamediated modulation of synaptic transmission in rat cerebellum. European Journal of Neuroscience 12 2497-2504.

Liu Z, Geng L, Li R, He X, Zheng JQ \& Xie Z 2003 Frequency modulation of synchronized Ca2 + spikes in cultured hippocampal networks through G-protein-coupled receptors. Journal of Neuroscience 23 4156-4163.

Ludwig M \& Pittman QJ 2003 Talking back: dendritic neurotransmitter release. Trends in Neurosciences 26 255-261.

Luster AD 1998 Chemokines - chemotactic cytokines that mediate inflammation. New England Journal of Medicine 338 436-445.

Luther SA \& Cyster JG 2001 Chemokines as regulators of T cell differentiation. Nature Immunology 2 102-107.

Ma Q Jones D, Borghesani PR, Segal RA, Nagasawa T, Kishimoto T, Bronson RT \& Springer TA 1998 Impaired B-lymphopoiesis, myelopoiesis, and derailed cerebellar neuron migration in CXCR4and SDF-1-deficient mice. PNAS 95 9448-9453.

Madden SL, Cook BP, Nacht M, Weber WD, Callahan MR, Jiang Y, Dufault MR, Zhang X, Zhang W, Walter-Yohrling J et al. 2004 Vascular gene expression in nonneoplastic and malignant brain. American Journal of Pathology 165 601-608.

McGeer PL \& McGeer EG 2004 Inflammation and the degenerative diseases of aging. Annals of the New York Academy of Sciences 1035 104-116.

McGrath KE, Koniski AD, Maltby KM, McGann JK \& Palis J 1999 Embryonic expression and function of the chemokine SDF-1 and its receptor, CXCR4. Developmental Biology 213 442-456.

Mellado M, Rodriguez-Frade JM, Vila-Coro AJ, Fernandez S, Martin de Ana A, Jones DR, Toran JL \& Martinez AC 2001 Chemokine receptor homo- or heterodimerization activates distinct signaling pathways. EMBO Journal 20 2497-2507.

Mentlein R 1999 Dipeptidyl-peptidase IV (CD26)-role in the inactivation of regulatory peptides. Regulatory Peptides 85 9-24.

Meucci O, Fatatis A, Simen AA, Bushell TJ, Gray PW \& Miller RJ 1998 Chemokines regulate hippocampal neuronal signaling and gp120 neurotoxicity. PNAS 95 14500-14505. 
Murphy PM, Baggiolini M, Charo IF, Hebert CA, Horuk R, Matsushima K, Miller LH, Oppenheim JJ \& Power CA 2000 International union of pharmacology, XXII. Nomenclature for chemokine receptors. Pharmacological Reviews 52 145-176.

Nagasawa T, Tachibana K \& Kishimoto T 1998 A novel CXC chemokine PBSF/SDF-1 and its receptor CXCR4: their functions in development, hematopoiesis and HIV infection. Seminars in Immunology 10 179-185.

Nahon JL 2006 The melanocortins and melanin-concentrating hormone in the central regulation of feeding behavior and energy homeostasis. Comptes Rendus Biologies 329 623-638.

Ohtani Y, Minami M, Kawaguchi N, Nishiyori A, Yamamoto J, Takami S \& Satoh M 1998 Expression of stromal cell-derived factor-1 and CXCR4 chemokine receptor mRNAs in cultured rat glial and neuronal cells. Neuroscience Letters 249 163-166.

Percherancier Y, Berchiche YA, Slight I, Volkmer-Engert R, Tamamura H, Fujii N, Bouvier M \& Heveker N 2005 Bioluminescence resonance energy transfer reveals ligand-induced conformational changes in CXCR4 homo- and heterodimers. Journal of Biological Chemistry 280 9895-9903.

Pillarisetti K \& Gupta SK 2001 Cloning and relative expression analysis of rat stromal cell derived factor-1 (SDF-1) 1: SDF-1 alpha mRNA is selectively induced in rat model of myocardial infarction. Inflammation 25 293-300.

Plata-Salaman CR 2001 Cytokines and feeding. International Journal of Obesity and Related Metabolic Disorders 25 S48-S52.

Proost P, Struyf S, Schols D, Durinx C, Wuyts A, Lenaerts JP, De Clercq E, De Meester I \& Van Damme J 1998 Processing by CD26/dipeptidyl-peptidase IV reduces the chemotactic and anti-HIV-1 activity of stromal-cell-derived factor-1alpha. FEBS Letters 432 73-76.

Ragozzino D 2002 CXC chemokine receptors in the central nervous system: role in cerebellar neuromodulation and development. Journal of Neurovirology 8 559-572.

Rodriguez-Frade JM, Mellado M \& Martinez AC 2001 Chemokine receptor dimerization: two are better than one. Trends in Immunology 22 612-617.

Sadir R, Baleux F, Grosdidier A, Imberty A \& Lortat-Jacob H 2001 Characterization of the stromal cell-derived factor-1alpha-heparin complex. Journal of Biological Chemistry 276 8288-8296.

Sadir R, Imberty A, Baleux F \& Lortat-Jacob H 2004 Heparan sulfate/heparin oligosaccharides protect stromal cell-derived factor-1 (SDF-1)/CXCL12 against proteolysis induced by CD26/dipeptidyl peptidase IV. Journal of Biological Chemistry 279 43854-43860.

Sergeyev V, Broberger C \& Hokfelt T 2001 Effect of LPS administration on the expression of POMC, NPY, galanin, CART and MCH mRNAs in the rat hypothalamus. Brain Research. Molecular Brain Research 90 93-100.

Stoehr JD, Cramer CP \& North WG 1992 Oxytocin and vasopressin hexapeptide fragments have opposing influences on conditioned freezing behavior. Psychoneuroendocrinology 17 267-271.

Streit WJ, Conde JR \& Harrison JK 2001 Chemokines and Alzheimer's disease. Neurobiology of Aging 22 909-913.

Stumm RK, Rummel J, Junker V, Culmsee C, Pfeiffer M, Krieglstein J, Hollt V \& Schulz S 2002 A dual role for the SDF-1/CXCR4 chemokine receptor system in adult brain: isoform-selective regulation of SDF-1 expression modulates CXCR4-dependent neuronal plasticity and cerebral leukocyte recruitment after focal ischemia. Journal of Neuroscience 22 5865-5878.

Stumm RK, Zhou C, Ara T, Lazarini F, Dubois-Dalcq M, Nagasawa T, Hollt V \& Schulz S 2003 CXCR4 regulates interneuron migration in the developing neocortex. Journal of Neuroscience 23 5123-5130.
Tachibana K, Hirota S, Iizasa H, Yoshida H, Kawabata K, Kataoka Y, Kitamura Y, Matsushima K, Yoshida N, Nishikawa S et al. 1998 The chemokine receptor CXCR4 is essential for vascularization of the gastrointestinal tract. Nature 393 591-594.

Tanabe S, Heesen M, Yoshizawa I, Berman MA, Luo Y, Bleul CC, Springer TA, Okuda K, Gerard N \& Dorf ME 1997 Functional expression of the CXC-chemokine receptor- 4 /fusin on mouse microglial cells and astrocytes. Journal of Immunology 159 905-911.

Tashiro K, Tada H, Heilker R, Shirozu M, Nakano T \& Honjo T 1993 Signal sequence trap: a cloning strategy for secreted proteins and type I membrane proteins. Science 261 600-603.

Toth PT, Ren D \& Miller RJ 2004 Regulation of CXCR4 receptor dimerization by the chemokine SDF-lalpha and the HIV-1 coat protein gp120: a fluorescence resonance energy transfer (FRET) study. Journal of Pharmacology and Experimental Therapeutics 310 8-17.

Tran PB \& Miller RJ 2003 Chemokine receptors: signposts to brain development and disease. Nature Reviews. Neuroscience 4 444-455.

Valenzuela-Fernandez A, Planchenault T, Baleux F, Staropoli I, Le-Barillec K, Leduc D, Delaunay T, Lazarini F, Virelizier JL, Chignard M et al. 2002 Leukocyte elastase negatively regulates Stromal cell-derived factor-1 (SDF-1)/CXCR4 binding and functions by amino-terminal processing of SDF-1 and CXCR4. Journal of Biological Chemistry 277 15677-15689.

Veldkamp CT, Peterson FC, Pelzek AJ \& Volkman BF 2005 The monomer-dimer equilibrium of stromal cell-derived factor-1 (CXCL 12) is altered by $\mathrm{pH}$, phosphate, sulfate, and heparin. Protein Science 14 1071-1081.

Vila M, Jackson-Lewis V, Guegan C, Wu DC, Teismann P, Choi DK, Tieu K \& Przedborski S 2001 The role of glial cells in Parkinson's disease. Current Opinion in Neurology 14 483-489.

Vila-Coro AJ, Rodriguez-Frade JM, Martin De Ana A, Moreno-Ortiz MC, Martinez AC \& Mellado M 1999 The chemokine SDF-lalpha triggers CXCR4 receptor dimerization and activates the JAK/STAT pathway. FASEB Journal 13 1699-1710.

Zhang WB, Navenot JM, Haribabu B, Tamamura H, Hiramatu K, Omagari A, Pei G, Manfredi JP, Fujii N, Broach JR et al. 2002 A point mutation that confers constitutive activity to CXCR4 reveals that T140 is an inverse agonist and that AMD3100 and ALX40-4C are weak partial agonists. Journal of Biological Chemistry 277 24515-24521.

Zhang K, McQuibban GA, Silva C, Butler GS, Johnston JB, Holden J, Clark-Lewis I, Overall CM \& Power C 2003 HIV-induced metalloproteinase processing of the chemokine stromal cell derived factor1 causes neurodegeneration. Nature Neuroscience 6 1064-1071.

Zheng J, Thylin MR, Ghorpade A, Xiong H, Persidsky Y, Cotter R, Niemann D, Che M, Zeng YC, Gelbard HA et al. 1999 Intracellular CXCR4 signaling, neuronal apoptosis and neuropathogenic mechanisms of HIV-1-associated dementia. Journal of Neuroimmunology 98 185-200.

Zigmond MJ 1997 Do compensatory processes underlie the preclinical phase of neurodegenerative disease? Insights from an animal model of parkinsonism Neurobiology of Disease 4 247-253.

Zlatopolskiy A \& Laurence J 2001 'Reverse gear' cellular movement mediated by chemokines. Immunology and Cell Biology 79 340-344.

Zou YR, Kottmann AH, Kuroda M, Taniuchi I \& Littman DR 1998 Function of the chemokine receptor CXCR4 in hematopoiesis and in cerebellar development. Nature 393 595-599.

Received in final form 19 October 2006

Accepted 20 November 2006

Made available online as an Accepted Preprint 28 December 2006 